\title{
ФУНКЦИОНИРОВАНИЕ И РАЗВИТИЕ ИНТЕЛЛЕКТУАЛЬНОГО И ИННОВАЦИОННОГО КАПИТАЛОВ В СОВРЕМЕННОЙ ПРОИЗВОДСТВЕННОЙ СФЕРЕ
}

\author{
(c) 2019 Левченко Лариса Владимировна \\ кандидат экономических наук, доцент \\ Самарский государственный экономический университет, Россия, Самара \\ E-mail: lvls@mail.ru \\ (c) 2019 Карпенко Ольга Анатольевна \\ ведущий специалист \\ АО «СамГЭС» (Самарагорэнергосбыт), Россия, Самара
}

В работе проводится исследование процессов функционирования и развития интеллектуального и инновационного капиталов в условиях современного интеллектуального производства. При этом рассматривается сам процесс современного интеллектуального производства, его разновидности и особенности создания вновь созданной стоимости, выявляются и анализируются его ключевые особенности и характеристики. По мере исследования участия знаний в производственном процессе выявляются изменения в современном процессе труда и деятельности. Также проводится статистическое исследование инновационной деятельности современных предприятий и получаемых доходов на инновационный капитал.

Ключевые слова: человеческий капитал, интеллектуальный капитал, инновационный капитал, вновь созданная стоимость, общественное производство, овеществленный и живой труд, конкретный и абстрактный труд, искусственный интеллект.

Основу современного общественного производства постепенно начинает составлять интеллектуальный капитал. Вместе с тем главной движущей силой развития современных высокоинтеллектуальных производств уже становится даже не интеллектуальный капитал, а капитал инновационный.

При всем многообразии исследований проблем развития интеллектуального и инновационного капиталов человека до настоящего времени отсутствует общая концепция функционирования и развития инновационного капитала как разновидности интеллектуального. В связи с этим на данный момент наиболее актуальным становится исследование развития и функционирования инновационного человеческого капитала, в качестве которых выступают получатели образования, исследователи-разработчики интеллектуальных продуктов, бизнес-сообщество и представители власти. Инновационный и интеллектуальный капиталы тесно функционируют и взаимодействуют в современном интеллектуальном производстве. Рассмотрим его более подробно, начиная с общественного производства.

Общественное производство - это продол- жение процессов информационного и материального обогащения в новой, сознательной форме. В настоящее время общественное производство - это прежде всего производство информации [1, С. 157-158]. Всякое общественное производство включает в себя две основные сферы: идеальное производство и материальное. Идеальное производство представляет собой исходную точку, производство начинается с познания свойств реального мира, фиксации, хранения и тиражирования этого знания в символах [1, С. 159]. При этом принципиальное различие между идеальным и материальным производством вытекает из различия идеальной и материальной природы информации. Материальное производство - это изменение параметров объектов, данных природой с целью их адаптации к человеческим потребностям. Идеальное производство не обходится без материального, данного непосредственно природой, или, в конечном счете, происходящего из нее. Но любое производство, как и любой другой процесс, начинается как идеальное (мысленно), а затем уже переходит в материальное.

Особенностью современной экономики является превращение человека одновременно 
в цель, в средство, и в условие экономической деятельности. В ней преобладающим звеном становится интеллектуальное производство, сочетающее в себе одновременно производственный и научно-исследовательский процесс, направленный не на простое тиражирование готовой продукции по заданным параметрам, а на непрерывное совершенствование самих технологий и поиск новых решений в процессе производства [2]. Простое тиражирование представляет собой, по-нашему мнению, обычный производственный процесс, это не интеллектуальное производство. А интеллектуальное производство - это создание в производственном процессе самих интеллектуальных технологий, решений, продуктов и услуг. Аналогично существует понятие инновационного производства как создание и внедрение инноваций и инновационных продуктов и услуг. Отсюда можно заметить, что интеллектуальное производство включает в себя инновационное.

В производстве интеллектуальных продуктов, услуг и технологий присутствует как абстрактный (овеществленный) труд, создающий стоимость, так и конкретный (живой) труд, определяющий стоимость потребительную. По мнению Вальтуха К.К., в условиях интеллектуального производства, создающего уникальные продукты и услуги преимущественно в результате творческого труда, первостепенное значение имеет в большей степени живой человеческий труд [3] (которым создается потребительная стоимость), особенно его качество, интенсивность, а также сам творческий процесс и творческий потенциал человека.

Новая стоимость товара и его потребительная стоимость здесь создаются именно интеллектуальным капиталом людей - сотрудников предприятия (разрабатываются новые модели и системы, инновационные подходы, вносятся новые решения и изменения). Стоимость создается посредством человеческой интеллектуальной деятельности, основанной на знаниях, мотивации и затратах творческой энергии, которые имеют свою цену. Аналогичным образом, инновационным капиталом создается стоимость товаров и услуг с высокой долей инноваций.

Высокая составляющая знаний в структуре интеллектуального и инновационного капиталов, благодаря которым непосредственно создается стоимость товаров и услуг, приводит к тому, что при исследовании создания ими стоимости возникают следующие моменты.

Во-первых, знаниями может непосредственно создаваться вновь созданная стоимость (например, новое изобретение). При этом, по мнению Вальтуха К.К. [1, С. 159-162], в отношении знаний в процессе производства происходит уже не создание, а перенос стоимости от человека на интеллектуальный продукт. На наш взгляд, стоимость знаний может переноситься идеально в случае, если это вид нематериального производства, а если присутствует создание материальных носителей, то идет перенос идеальной составляющей стоимости с одновременным созданием стоимости материальной. То есть явление переноса стоимости можно рассматривать в идеальной форме, а в материальной форме происходит постоянное создание новой стоимости продукта.

При этом, заметим, что стоимость возникает и сохраняется при создании интеллектуальных продуктов посредством интеллектуальной деятельности. И сама стоимость создается уже в большей степени не трудом, а деятельностью.

Во-вторых, сами знания могут и не создавать стоимости, а стоимость товаров и услуг может вытекать просто из ограничения доступа к знаниям (например, знание о том, как написать программу взаимодействия различных нейронных сетей между собой, или знание о специфике открытия новой линии производства). Здесь меновая стоимость знания вытекает из ограничения доступа к нему и целиком зависит от практической возможности ограничить его свободное потребление. Но это просто случай монополии и возникновения фиктивности интеллектуального капитала, фиктивности самих знаний. И здесь речь не идет о создании новой стоимости, а лишь о монопольном присвоении ранее созданного дохода.

В-третьих, собственная мера стоимости и ценности самих знаний находится в зависимости от того, на какой основе происходит их обмен.

Если обмен знаниями идет на возмездной основе, то мера их стоимости, которую будут давать за них при обмене, и будет являться ценностью знаний на данный момент времени.

Если же обмен знаниями происходит на безвозмездной основе (или возмездной, но не в денежном эквиваленте), и обогащает обе стороны, то, по мнению А. Горца [4], по отношению к стоимости самих знаний целесообразнее опериро- 
вать даже не категорий стоимости (или меновой стоимости), а категорией абсолютной ценности, не выражающейся в денежном эквиваленте.

Далее А. Горц считает возможным предположить, что сейчас именно содержание знаний (конкретное знание, а не абстрактный труд) становится важнейшей общественной субстанцией всех товаров и услуг, источником стоимости и прибыли. Они не могут быть сведены к определенному количеству общественного абстрактного труда, т.к. неотрывно охватывают всевозможные разнородные знания и понимание действительности, сопряженное с его интеллектуальными и духовными качествами, способностью к самообучению и работе над собой (например, интуитивное знание, предположения, сообразительность и понимание действительности).

По-нашему мнению, по отношению к стоимости самих знаний целесообразнее использовать категорию ценности. Также возможно, что в будущем предметом экономических исследований станет конкретное знание и категория самой человеческой деятельности (вместо категории человеческого труда): интеллектуальной, инновационной, научно-практической и научно-прикладной деятельности, посредством которой создается стоимость товаров. При этом созданные товары и услуги имеют как свою цену на рынке (а значит, и стоимость), так и вне рынка (они имеют свою ценность для человека и свою потребительную стоимость). Здесь знаниями создается стоимость, но уже не напрямую как затраты человеческого труда, а как затраты человеческой интеллектуальной деятельности, его времени, сил и энергии. Не оперируя понятием труда как такового, можно предположить, что человеческая деятельность в экономике это деятельность по применению знаний ввиду их общественной необходимости и производительности, которая также имеет в своем составе абстрактную деятельность (аналог абстрактного труда и предпосылка стоимости) и конкретную деятельность (аналог конкретного труда и предпосылка стоимости потребительной).

В данном случае формальные и отделимые от человека знания на производстве могут играть роль постоянного капитала ввиду того, что они увеличивают прибыль и снижают издержки: экономят общественный труд и снижают меновую стоимость создаваемых продуктов и услуг. А знания, неотделимые от человека, неформаль- ные (понимание действительности, интуитивное знание, предвидение и т.п.) - соответственно, могут быть аналогом капитала переменного.

Таким образом, знания могут полностью превратиться в нематериальный капитал, и затем их реализация происходит уже в рыночных условиях путем установления цены и определенной монополии на них. Причем монополизация знаний зачастую требует больших затрат времени, финансов, трансакционных издержек, чем производство самих продуктов и услуг. И нематериальный капитал многих современных компаний, состоящий во основном из интеллектуального капитала, уже в основном является монополией на знания.

Монополия на знания тесно связана с отношениями собственности на них. Собственник интеллектуального капитала в экономических отношениях выступает в качестве наемного работника, и в редких случаях - в качестве совладельца фирмы. А собственником фирмы выступает предприниматель и инвесторы, финансирующие интеллектуальные разработки и их внедрение, и также имеющие право на долю прибыли (в случае акционерных обществ).

В связи с тем, что в современной экономике и в научной экономической мысли происходит трансформация экономических категорий «труда» в «деятельность», «стоимости» в «ценность», «работы» в «применение знаний»,- соответствующие изменения претерпевает и институт рынка. По мнению А.В. Бузгалина, значительная часть современных экономических отношений уже представляет собой нерыночные отношения, однако этот вопрос мало затрагивается в научной исследовательской литературе. В странах с социально ориентированной моделью капитализма (Скандинавские страны, Австрия и др.) вне отношений товарного производства уже лежит создание и потребление почти половины всех благ [5]. Это касается образования (бюджетные места и бесплатное обучение), спорта, медицины, науки, деятельности общественных организаций и волонтеров, значительной части информационной деятельности (бесплатные библиотеки и интернет) и др. Здесь общество получает ресурсы от налогов с наиболее богатых слоев населения, а работники большей частью заняты творческой деятельностью и производством общественных благ. Человек уже может заниматься своей деятельностью и творчеством на благо семьи и общества, иметь достаточно вре- 
мени для реализации своих намерений и планов и при этом ни в чем не нуждаться, практически имея все необходимое. Причем, заметим, что само создание общественных, а также социально-значимых благ свидетельствует о духовном развитии человека. По мнению же Цветкова А., и вовсе, все, что можно раздавать, не теряя, не должно продаваться [6], а должно нормировано распределяться, превращаясь в закрытые привилегии, в отличие от частной интеллектуальной собственности.

В развитых западных странах и в России еще одной важной особенностью современного интеллектуального производства является массовое применение в экономических системах информационных цифровых технологий и искусственного интеллекта. Искусственный интеллект ведет к сильнейшей оптимизации производственных и информационно-аналитических процессов, упрощению отношений с потребителями и клиентами, совершенствованию кадровой работы,- ведет к оптимизации всех процессов, превращению продуктов в сервисы и даже к смене бизнес-модели многих предприятий [7].

В отношении же человека одной из главнейших тенденций, в том числе и на рабочем месте (на производстве), становится непрерывное обучение, образование, повышение квалификации и развитие дополнительных навыков и знаний. По словам Ксавье Беттеля, премьер-министра Люксембурга: «Главное ... инвестируйте в образование своих людей! За час я не научусь кататься на коньках, я буду падать и падать, но в конечном итоге - буду кататься. То же самое происходит и с новой интеллектуальной экономикой» [8].

В настоящее время человек, отличаясь от искусственного интеллекта, учится постоянному, системному и инновационному мышлению, выходу за рамки стандартов и стереотипов. Он самостоятельно ставит себе новые задачи, ищет выходы из сложившихся ситуаций и при этом всесторонне развивается. В идеале нужно стремиться ко всестороннему развитию всех подвидов своего человеческого капитала. В современных крупных компаниях существует практика не только обучения сотрудников, но также их культурное развитие (походы в театр, выезды на природу, экскурсии, посещение библиотек), спортивные мероприятия, творческие занятия во внерабочее время, творческие конкурсы, ме- роприятия, досуг детей и многое другое.

Далее, переходя от теории к практике, проведем исследование показателей инновационной деятельности современных организаций в динамике. За 2017 год произошел небольшой и несущественный рост инновационной активности организаций, а также вырос удельный вес организаций, осуществляющих технологические инновации. При этом объем инновационных товаров, работ и услуг с 2015 по 2017 сохранился на прежнем уровне. Если с 2014 года наблюдалось снижение количества выданных патентных заявок, то в 2018 они возросли на 4\%. Выросло и число созданных производственных технологий на $11 \%$, а также число используемых передовых производственных технологий - на 3,5\%. Вместе с тем на 9\% увеличились затраты на технологические инновации. Таким образом, по инновационному потенциалу и деятельности в современном производстве, наблюдается рост показателей.

При внедрении научно-исследовательских результатов на производстве и создании новых предприятий помимо трансакционных издержек поиска информации для сторон-участников процесса неизбежны проблемные ситуации, которые в общем можно сформулировать в виде трех блоков:

1. трудности, связанные с поиском финансирования проектов,

2. проблемы юридического характера, связанные с оформлением и защитой прав интеллектуальной собственности и др.,

3. недостаточное развитие институциональных условий, институтов и механизмов стимулирования коммерциализации новых идей и разработок.

Решение указанных проблем требует комплексного подхода со стороны образовательных учреждений, общественных организаций, органов власти и корпораций. Для поднятия престижа науки среди молодежи и роста научного потенциала можно предложить несколько направлений решения проблем:

1. Стимулирование учеников и студентов на занятие научной и инновационной деятельностью (материально - путем присуждения премий за удачные разработки и нематериально - с помощью выдачи грамот, поздравлений), а ВУЗов - на введение льгот для тех учеников, кто на протяжении школьных лет занимался разработками или исследовательской деятель- 
Таблица 1. Показатели инновационной деятельности организаций в динамике за последние годы

\begin{tabular}{|c|c|c|c|c|c|c|}
\hline № & Показатели / Годы & 2014 & 2015 & 2016 & 2017 & 2018 \\
\hline \multirow[t]{2}{*}{1} & $\begin{array}{l}\text { Инновационная активность } \\
\text { организаций (удельный вес } \\
\text { организаций, осуществлявших } \\
\text { технологические, организаци- } \\
\text { онные, маркетинговые инно- } \\
\text { вации в отчетном году), в\% }\end{array}$ & 9,9 & 9,3 & 8,4 & 8,5 & \\
\hline & Темп роста,\% & & 93,94 & 90,32 & 101,19 & \\
\hline \multirow[t]{2}{*}{2} & $\begin{array}{l}\text { Удельный вес организаций, } \\
\text { осуществлявших технологи- } \\
\text { ческие инновации в отчетном } \\
\text { году }\end{array}$ & 8,8 & 8,3 & 7,3 & 7,5 & \\
\hline & Темп роста,\% & & 94 & 88 & 103 & \\
\hline \multirow[t]{2}{*}{3} & $\begin{array}{l}\text { Объем инновационных това- } \\
\text { ров, работ, услуг по Российской } \\
\text { Федерации, в млн. руб. }\end{array}$ & 41233490,9 & 45525133,8 & 51316283,5 & 57611057,8 & \\
\hline & Темп роста,\% & & 110,41 & 112,72 & 112,27 & \\
\hline \multirow[t]{2}{*}{4} & $\begin{array}{l}\text { Затраты на технологические } \\
\text { (продуктовые, процессные) } \\
\text { инновации в млн. руб. }\end{array}$ & 1211897098,1 & 1203638084,3 & 1284590,3 & 1404985,3 & \\
\hline & Темп роста,\% & & 99,32 & 0,11 & 109,37 & \\
\hline \multirow[t]{2}{*}{5} & $\begin{array}{l}\text { Поступление патентных } \\
\text { заявок и выдача охранных } \\
\text { документов в России }\end{array}$ & 40308 & 45517 & 41587 & 36454 & 37957 \\
\hline & Темп роста,\% & & 112,92 & 91,37 & 87,66 & 104,12 \\
\hline \multirow[t]{2}{*}{6} & $\begin{array}{l}\text { Число созданных (разрабо- } \\
\text { танных) передовых производ- } \\
\text { ственных технологий }\end{array}$ & 1409 & 1398 & 1534 & 1402 & 1565 \\
\hline & Темп роста,\% & & 99,22 & 109,73 & 91,40 & 111,63 \\
\hline 7 & $\begin{array}{l}\text { Число используемых пере- } \\
\text { довых производственных } \\
\text { технологий }\end{array}$ & 2445 & 3314 & 3751 & 3787 & 3922 \\
\hline & Темп роста,\% & 135,54 & 113,19 & 100,96 & 103,56 & \\
\hline
\end{tabular}

Составлено и рассчитано по данным федеральной службы государственной статистики URL: http://www.gks.ru/wps/wcm/ connect/rosstat_main/rosstat/ru/statistics/science/\#

ностью и преподавателей на участие их студентов в научно-практических мероприятиях.

2. Активное привлечение молодежи в научные исследования в учебных заведениях, а также развитие научных организаций и проведение научных исследований, имеющих выраженную социальную направленность.

3. Развитие высшего и послевузовского образования, ведь оно является фундаментом для развития научных кадров. Кроме того, особенностью современной жизни и процессов формирования интеллектуального капитала является постоянная необходимость повышения образовательного уровня и прохождения дополнительного образования. А в связи с появлением искусственного интеллекта и автоматизацией многих процессов - возможно, и потребность в новой профориентации, переобучении и переквали- фикации. Также в современном мире нарастает всеобщая необходимость повышения финансовой, юридической и информационно-технологической грамотности.

Вместе с тем в настоящее время наблюдаются изменения и в самом человеческом сознании, формируется новый тип сознания, характеризующийся повышением значимости эмоционального и духовного интеллекта, развитием инновационного мышления, повышением осознанности и ускорением всех видов общения и взаимодействия между людьми. Постоянное развитие интеллекта и приложение ко всему новых решений, что в конечном итоге уже привело к проникновению инновационного сознания в реальную жизнь и во все сферы общества: появление гаджетов и совершенствование бытовых приборов, массовое применение IT-технологий, 
развитие у детей и молодежи инновационных навыков сознания, мышления. В будущем подобная тенденция может привести ко все более массовому развитию инновационного мышления и даже научного сознания, которые могут стать частью повседневности.

Обучение и интеллектуальное развитие в современном мире прежде всего нацелено на получение отдачи на интеллектуальный капитал. Результаты применения интеллектуального и инновационного капитала на предприятиях представлены интеллектуальными доходами, принимающими форму заработной платы, прибыли и ренты. Соответственно, использование интеллектуального капитала на основании интеллектуальных доходов может характеризоваться следующими показателями: среднемесячной заработной платой персонала, занятого исследованиями и разработками, объемом интеллектуальной ренты на предприятиях, а также отношением ее к численности персонала, занятого исследованиями.

По данным Росстата, среднемесячная заработная плата работников, выполняющих исследования и разработки, имеет положительную динамику и в 2017 г. на 25\% превысила значение общего показателя по экономике. По сравнению со странами ЕС расхождение в заработной плате на 2017 год составляет более, чем в 3 раза (Таблицы 2, 3).

Таким образом, цели и задачи интеллектуального производства могут достигаться и высокоэффективно решаться в обществе и в экономике, только, если одновременно с этим осуществляются цели человеческого развития, духовного, инновационного и интеллектуального.

Переходя к исследованию показателя интеллектуальной ренты, отметим, что в России рентные потоки доходов довольно распространены и им принадлежит основной вклад в прирост совокупного дохода (а не труду и капиталу, как во многих странах): в среднем около 75\% доходов имеют рентное происхождение [10], однако практика ведения учета, распределения и оценки интеллектуальных доходов и интеллектуальной ренты фактически отсутствует.

Экономическое развитие России всегда сопровождалось стремлением к монопольному присвоению рентных доходов. В данный момент

Таблица 2. Показатели российской среднемесячной оплаты труда населения, занятого исследованиями и разработками за последние годы

\begin{tabular}{|l|c|c|}
\hline \multicolumn{1}{|c|}{ Показатели } & 2017 & 2018 \\
\hline $\begin{array}{l}\text { Среднемесячная начисленная номинальная заработная плата по полному } \\
\text { кругу организаций в целом по экономике, руб. }\end{array}$ & 39167 & 43724 \\
\hline Тр,\% & & 111,6 \\
\hline из нее деятельность профессиональная, научная и техническая & 57178,8 & 66264 \\
\hline Тр,\% & & 115,9 \\
\hline из нее научные исследования и разработки & 66177,9 & 75913 \\
\hline Тр,\% & & 114,7 \\
\hline
\end{tabular}

По данным федеральной службы государственной статистики URL: http:/www.gks.ru/wps/wcm/connect/rosstat main/rosstat/ ru/statistics/wages/; Индикаторы науки: 2019: статистический сборник / Л.М. Гохберг, К.А. Дитковский, Е.Л. Дьяченко и др.; Нац. исслед. ун-т «Высшая школа экономики».- М.: НИУ ВШЭ, 2019.

Таблица 3. Показатели российской среднемесячной оплаты труда в сравнении со странами ЕС за последние годы [9]

\begin{tabular}{|c|c|c|c|}
\hline Показатели & 2015 & 2016 & 2017 \\
\hline $\begin{array}{l}\text { Среднемесячная заработная плата населения, занятого исследова- } \\
\text { ниями и разработками в России, руб. }\end{array}$ & 41512 & 43540 & 48834 \\
\hline $\mathrm{Tp}, \%$ & & 105 & 112 \\
\hline $\begin{array}{l}\text { Среднемесячная заработная плата населения, занятого исследова- } \\
\text { ниями и разработками в ЕС, долл. }\end{array}$ & 2338 & 2546 & 2600 \\
\hline $\begin{array}{l}\text { Среднемесячная заработная плата населения, занятого исследова- } \\
\text { ниями и разработками в России, долл. }\end{array}$ & 638,646 & 669,846 & 751,292 \\
\hline
\end{tabular}


это приводит к тому, что нерентные в классическом понимании факторы (инновации, власть) преобразуются в рентные и обеспечивают возможность получения административной и других видов неприродной ренты экономическими субъектами, что обуславливает преобладание рентных экономических интересов.

Из показателя общей интеллектуальной ренты ввиду отсутствия статистики по практическим выплатам разнообразных доходов собственников всего интеллектуального капитала представляется возможным оценить объем инновационной ренты (как частного случая интеллектуальной ренты). Для собственника интеллектуального капитала инновационная рента на практике может выражаться в виде роялти, исчисляемого в процентном отношении от балансовой прибыли лицензиата или от валового объема реализации лицензионной продукции [11]. Расчетный показатель инновационной ренты может определяться как:

- избыток над средней прибылью фирмы (доход инноватора) - разность между избыточной прибылью (вследствие тиражирования инноваций через продажу лицензий и превышение спроса над предложением) и средней прибылью инновационной фирмы (микроуровень);

- сумма от продажи новой продукции - патентов, лицензий и ноу-хау - по более высоким ценам и от прироста капитальной оценки интеллектуально активных предприятий (макроуровень) [12];

- суммарная доля интеллектуальной составляющей в цене продукции (28-32\%) или рентабельности высокотехнологичных компаний
(30-40\%) [13];

- произведение вклада ученых в ВВП на коэффициент результативности исследовательского интеллектуального труда, в среднем равный 3, так как по имеющимся данным за средний период исследовательской деятельности около 3 разработок достигают стадии принесения дохода [14]. Иными словами, производительность интеллектуального производства в России составляет примерно 3 проекта из 100, а «основная масса технологий 97-99\% потенциально способны к коммерциализации, но не доходят до рынка» [15]. IR = Численность исследователей $\times$ К продуктивности $\times$ ВВП на одного занятого в экономике. Итак, воспользовавшись последним методом, рассчитаем объем инновационной ренты в РФ за последние годы (Таблица 4).

Из Таблицы мы видим, что объем инновационной ренты на 2017 год составляет свыше 27 млрд. руб., или 417 млн. долл. Можно отметить, что по сравнению с нашим исследованием, проведенным по итогам 2009-2010 годов, ее объем увеличился более, чем в 5 раз (ранее показатель составлял около 5 млрд. долл.) [16]. Особенно показатель ренты возрос в 2017 году - на 6\%.

В итоге проведенного исследования можно констатировать, что несмотря на существующие проблемы, за последний пятилетний период развития нашего государства ввиду произошедшего увеличения показателей как инновационной деятельности организаций, так и доходов на инновационный капитал, производственная сфера продолжает развиваться в современном интеллектуально-инновационном направлении.

Таблица 4. Расчетный объем инновационной ренты России за 2014-2017 гг.

\begin{tabular}{|c|c|c|c|c|c|c|c|}
\hline Год & $\begin{array}{c}\text { Числен- } \\
\text { ность иссле- } \\
\text { дователей, } \\
\text { тыс. чел. }\end{array}$ & $\begin{array}{c}\text { Числен- } \\
\text { ность про- } \\
\text { дуктивных } \\
\text { исследова- } \\
\text { телей, чел. }\end{array}$ & $\begin{array}{c}\text { Объем ВВП, } \\
\text { млрд. руб. }\end{array}$ & $\begin{array}{c}\text { Числен- } \\
\text { ность } \\
\text { занятого } \\
\text { населения } \\
\text { (15-72 л.), } \\
\text { млн. чел. }\end{array}$ & $\begin{array}{c}\text { Объем ВВП } \\
\text { на одного } \\
\text { занятого в } \\
\text { экономике, } \\
\text { тыс. руб. }\end{array}$ & $\begin{array}{c}\text { Объем ин- } \\
\text { новацион- } \\
\text { ной ренты, } \\
\text { млн. руб. }\end{array}$ & $\begin{array}{c}\text { Объем ин- } \\
\text { новацион- } \\
\text { ной ренты, } \\
\text { млн. долл. }\end{array}$ \\
\hline \multirow[t]{2}{*}{1} & 2 & 3 & 4 & 5 & 6 & 7 & 8 \\
\hline & & гр.2×0,03 & & & гр.4/гр.5 & гр.3×гр.6 & гр.7/65 \\
\hline 2014 & 732,274 & 21,968 & 79199,7 & 71,539 & 1107,084 & 24320,670 & 374,164 \\
\hline 2015 & 738,857 & 22,166 & 83232,6 & 72,324 & 1150,830 & 25508,955 & 392,445 \\
\hline 2016 & 722,291 & 21,669 & 86043,9 & 72,393 & 1188,567 & 25754,728 & 396,227 \\
\hline \multirow[t]{2}{*}{2017} & 707,887 & 21,237 & 92101,3 & 72,142 & 1276,667 & 27112,076 & 417,109 \\
\hline & & & & & & 27 млрд & 417 млн \\
\hline
\end{tabular}

Рассчитано автором. Данные гр. 2-4 взяты на сайте Федеральной службы государственной статистики: гр. 5 http://www.gks. ru/bgd/regl/b18_61/Main.htm; гp. 2 URL: https://www.hse.ru/data/2019/05/07/1502498137/in2019 


\section{Библиографический список}

1. Вальтух К.К. Информационная теория стоимости и законы неравновесной экономики. М.: ООО «Янус-К»897 c.

2. Что такое интеллектуальная экономика и «интеллектуальное производство». Полит информация. Аналитика. Факты и комментарии. URL: http://politinform.su/analitika/1925-chto-takoe-intellektualnaya-ekonomikai-mozgoproizvodstvo.html

3. Салихов Б.В., Летунов Д.А. Интеллектуальная экономика как нравственно-этическая форма инновационного развития // Проблемы современной экономики, № 3 (27), 2008. URL: http://www.m-economy.ru/art. php?nArtId=2070

4. Гори А. Знание, стоимость и капитал. К критике экономики знаний. Философско-литературный журнал «ЛОГОС».— № 4(61). - 2007.- С. 2. URL: http://www.aitrus.info/node/643

5. Бузгалин А. В., Колганов А.И. Экономическая компаративистика. Сравнительный анализ экономических систем. М.: Проспект, 2016, 746с.; Бузгалин А.В. Будущее скандинавской модели (новый проект социально-ориентированного развития) // Альтернативы. 2011. - № 1.- С. 4-16.

6. Ц Цветков А. Мир через сто лет. Взгляд слева. 2016. URL: http://www.colta.ru/articles/society/11529

7. Искусственный интеллект (ИИ) / Artificial Intelligence (AI) как ключевой фактор цифровизации глобальной экономики URL: https://www.crn.ru/news/detail.php? ID=117544

8. Пока к власти не пришел искусственный интеллект - у нас есть шанс // Авторские колонки. URL: https:// rb.ru/opinion/interesno-na-otkrytyh-innovaciyah/

9. Россия и страны - члены Европейского союза. 2017: Стат.сб./ Р76 Росстат. - М., 2017. - 264 с.

10. Сергеев И., Кирсанова Н., Кирсанова И. Развитие социальной сферы: приоритеты регулирования // Экономист. 2007.- № 1.- С. 49.

11. Бовин, Андрей Андреевич Управление инновациями в организации: учеб. пособие п о специальности Менеджмент организации / А.А. Бовин, Л.Е. Чередникова, В.А. Якимович. - 3-е изд., стер.- М.: Издательство «Омега-Л», 2009.- 415 с. - С. 158.

12. Скоблякова И.В. Методология оценки интеллектуальной ренты как источника инно-вационных инвестиций // Интеллектуальные силы человечества и гармония мирового развития: Мат. международной интернет-конференции: Вып. II. Планетарная рента: Источники, виды, методология оценки (сентябрь 2006 - январь 2007 г.) - СПб., Орел: НЦ «Планетарный проект», ОрелГТУ, 2007.-С. 83-102.- С.92.

13. Кузьмина, 3.В. Формирование и распределение интеллектуальной ренты в современной российской экономике: дис. ...к.э.н. / З.В. Кузьмина.- Казань, 2010.-154 с.-С. 18.

14. Орбачевский Л. С. Стратегия коммерциализации научных заделов / Акад. нар. хоз-ва при Правительстве РФ. URL: http://www.intb.ru/index.phtml

15. Интервью руководителя ФС по интеллектуальной собственности «Роспатент» Б.П. Симонова. URL: http:// www.patentclub.ru/publications

16. Карпенко О.А. Формирование и использование интеллектуального капитала в современной экономике. Дисс.... к.э.н. Самара, 2011.-222с.- С. 129 